\title{
Mesquite bugs, other insects, and a bat in the diet of pallid bats in southeastern Arizona
}

\author{
Nicholas J Czaplewski ${ }^{\text {Corresp., }}{ }^{1}$, Katrina L Menard ${ }^{2}$, William D Peachey ${ }^{3}$ \\ ${ }^{1}$ Section of Vertebrate Paleontology, Oklahoma Museum of Natural History, Norman, Oklahoma, United States of America \\ 2 Section of Recent Invertebrates, Oklahoma Museum of Natural History, Norman, Oklahoma, United States \\ 3 Sonoran Science Solutions, Tucson, Arizona, United States \\ Corresponding Author: Nicholas J Czaplewski \\ Email address: nczaplewski@ou.edu
}

The pallid bat (Antrozous pallidus) is a species of western North America, inhabiting ecoregions ranging from desert to oak and pine forest. They are primarily insectivorous predators on large arthropods that occasionally take small vertebrate prey, and are at least seasonally omnivorous in certain parts of their geographic range where they take nectar from cactus flowers and eat cactus fruit pulp and seeds. Until recently, mesquite bugs were primarily tropical-subtropical inhabitants of Mexico and Central America but have since occupied the southwestern United States where mesquite trees occur. Using a noninvasive method, we investigated the bats' diet at the Cienega Creek Natural Preserve, Arizona, by collecting food parts discarded beneath three night roosts in soil-piping cavities in a mesquite bosque. We also made phenological and behavioral observations of mesquite bugs, Thasus neocalifornicus, and their interactions with the mesquite trees. We determined that the bats discarded inedible parts of 36 species in 8 orders of mainly largebodied and nocturnal insects below the night-roosts. In addition, one partial bat wing represents probable predation upon a phyllostomid bat, Choeronycteris mexicana. About 17 of the insect taxa are newly reported as prey for pallid bats, as is the bat $C$. mexicana. The majority of culled insect parts (88\%) were from adult mesquite bugs. Mesquite bug nymphs did not appear in the culled insect parts. After breeding in late summer, when nighttime low temperatures dropped below $21^{\circ} \mathrm{C}$, the adult bugs became immobile on the periphery of trees where they probably make easy prey for opportunistic foliage-gleaning pallid bats. Proximity of night-roosts to mesquite bug habitat probably also enhances the bats' exploitation of these insects in this location. 


\author{
MESQUITE BUGS, OTHER INSECTS, AND A BAT IN THE DIET OF PALLID BATS IN \\ SOUTHEASTERN ARIZONA \\ Nicholas J. Czaplewski, ${ }^{1}$ Katrina L. Menard, ${ }^{2}$ and William D. Peachey ${ }^{3}$ \\ ${ }^{1}$ Section of Vertebrate Paleontology, Oklahoma Museum of Natural History, University of \\ Oklahoma, Norman, Oklahoma, United States of America \\ ${ }^{2}$ Section of Recent Invertebrates, Oklahoma Museum of Natural History, University of \\ Oklahoma, Norman, Oklahoma, United States of America \\ ${ }^{3}$ Sonoran Science Solutions, Tucson, Arizona, United States of America
}

Corresponding author Nicholas J. Czaplewski, nczaplewski@ou.edu

\title{
ABSTRACT
}

The pallid bat (Antrozous pallidus) is a species of western North America, inhabiting ecoregions ranging from desert to oak and pine forest. They are primarily insectivorous predators on large arthropods that occasionally take small vertebrate prey, and are at least seasonally omnivorous in certain parts of their geographic range where they take nectar from cactus flowers and eat cactus fruit pulp and seeds. Until recently, mesquite bugs were primarily tropical-subtropical inhabitants of Mexico and Central America but have since occupied the southwestern United States where mesquite trees occur. Using a noninvasive method, we investigated the bats' diet at the Cienega Creek Natural Preserve, Arizona, by collecting food parts discarded beneath three night roosts in soil-piping cavities in a mesquite bosque. We also made phenological and behavioral observations of mesquite bugs, Thasus neocalifornicus, and their interactions with the mesquite trees. We determined that the bats discarded inedible parts of 36 species in 8 orders of mainly large-bodied and nocturnal insects below the night-roosts. In addition, one partial bat wing represents probable predation upon a phyllostomid bat, Choeronycteris mexicana. About 17 of the insect taxa are newly reported as prey for pallid bats, as is the bat $C$. mexicana. The majority of culled insect parts $(88 \%)$ were from adult mesquite bugs. Mesquite bug nymphs did not appear in the culled insect parts. After breeding in late summer, when nighttime low temperatures dropped below $21^{\circ} \mathrm{C}$, the adult bugs became immobile on the periphery of trees where they probably make easy prey for opportunistic foliage-gleaning pallid bats. Proximity of night-roosts to mesquite bug habitat probably also enhances the bats' exploitation of these insects in this location. 
42

43

44

45

46

47

48

49

50

51

52

53

54

55

56

57

58

59

60

61

62

63

64

65

66

67

68

69

70

71

72

73

74

75

76

77

78

79

80

81

82

83

84

85

86

\section{INTRODUCTION}

The pallid bat, Antrozous pallidus, is widespread in western North America in arid to semiarid, rocky habitats, open deserts, and oak and pine forest. Previous studies have shown that this species is generally a predator on arthropods, especially insects. However, pallid bats are opportunistic and flexible, occasionally taking fruit from organ pipe cactus (Stenocereus thurberi) and cardón (Pachycereus pringlei) in the Southwest, and at least incidentally, they also take pollen and nectar from flowering columnar cacti (Howell, 1980; Herrera et al., 1993; Simmons \& Wetterer, 2002; Frick et al., 2009, 2013, 2014; Aliperti et al., 2017) and probably agaves (Ammerman et al., 2012). Most often, pallid bats prey upon relatively large, flightless arthropods; occasionally they also eat small vertebrates (Engler, 1943; Orr, 1954; O'Shea \& Vaughan, 1977; Bell, 1982; Lenhart et al., 2010; Rambaldini \& Brigham, 2011). Some of these prey items are taken during a brief touchdown or are gleaned from foliage during flight. Pallid bats use a characteristic searching flight that usually involves relatively slow and maneuverable flying about $0.5-2.5 \mathrm{~m}$ above the ground while making rhythmic rises and dips interspersed with swoops and glides when the bat detects prey (O'Shea \& Vaughan, 1977). Occasionally the bats hover near low or thorny vegetation, or land on the ground where they are quite agile at using a variety of gaits and strides to pursue prey. This foraging style carries high risks of injury and predation for the bats, whose wing membranes and bones heal but show scars and deformities (Davis, 1968). While preying upon scorpions and centipedes they also endure venomous stings to the face and other body parts (Hopp et al., 2017). Previous authors (O'Shea \& Vaughan, 1977) showed that pallid bats eat arthropods that share at least two of four characteristics: (1) large size; (2) either obligatorily or primarily active on the ground surface; (3) fly weakly at low heights; or (4) fly strongly but often land on vegetation. The bats frequently retreat to a night roost to rest or manipulate and eat the prey they have caught. They alight on the ceilings of rock shelters, overhangs, or small grottos temporarily to process their prey. The bats drop undesired parts of the arthropods such as wings, elytra, and legs. The discarded items provide qualitative data on pallid bat diets (e.g., Orr, 1954; Ross, 1961, 1967; O'Shea \& Vaughan, 1977; Bell, 1982; Lenhart et al., 2010), although Johnston \& Fenton (2001) found that the insects represented in the culled parts were biased toward the hardest and largest prey species eaten relative to species represented in fecal pellets. In this study, we investigated food habits of pallid bats in southeastern Arizona and made observations on their interactions with the predominant insect in their local diet, the mesquite bug Thasus neocalifornicus. We add to the list of arthropod and vertebrate prey known to be taken by pallid bats. Importantly, we document observations relevant to an example of these bats feeding opportunistically on large numbers of mesquite bugs, as well as the first record in the wild of their feeding on another species of bat in southeastern Arizona. We also provide observations of certain mesquite bug behaviors that may increase their susceptibility to the foraging style of pallid bats.

As gleaning bats that hunt arthropods moving or resting on plant or ground surfaces, pallid bats have well-developed acoustical, olfactory, and visual senses. They mainly locate their prey by sound, either through active echolocation or passive detection of the faint sounds made by moving prey (O'Shea \& Vaughan, 1977). In experiments with insects and their pheromones other than those of mesquite bugs (Thasus spp.), pallid bats are also sensitive to olfactory cues and are able to distinguish prey odors from controls and from non-prey species (Johnston, 2002). The bats show selectivity upon closely approaching certain prey insects versus a non-prey noxious insect (the Pinacate beetle Eleodes: Tenebrionidae) or paper balls impregnated with their 
87 odors (Johnston, 2002). The bats also have relatively large eyes and high visual acuity at low 88 light levels (Bell \& Fenton, 1986).

89 Pallid bats previously were reported to take certain leaf-footed bugs (Heteroptera:

90 Coreidae) only occasionally. Coreids are globally distributed but mostly subtropical and tropical

91 insects, with about 80 species in the continental United States and Canada (Froeschner, 1988). One member genus, Thasus (Coreinae: Nematopini), has eight species primarily distributed in the Neotropics (Forbes \& Schaefer, 2003). Like many other Hemiptera, Coreidae are herbivores that suck the contents of plant tissues (Froeschner, 1988). Many coreids are also host specific, feeding on one or two families of plants (Froeschner, 1988). The only species of Thasus in the United States is Thasus neocalifornicus (giant mesquite bug); the species also occurs in Baja California and Sonora and Chihuahua, Mexico (Forbes \& Schaefer, 2003). The closely related species Thasus gigas and Thasus acutangulus occur further south in Mexico and Central America; these two species were once considered synonymous with $T$. neocalifornicus but have since been shown to be distinct (Brailovsky \& Barrera in Brailovsky et al., 1995; Forbes \& Schaefer, 2003). Thasus neocalifornicus is ecologically tied to mesquites (Prosopis, Fabaceae; De La Torre-Bueno, 1945; Ward et al., 1977; Schuh \& Slater, 1995; Brummermann, 2010). Mesquite trees have spread widely in the United States during the last two centuries along with cattle (Turner et al., 2003), providing the potential for the bugs to expand their geographic range. Schaefer \& Packauskas (1998) speculated that the United States populations of $T$. neocalifornicus in Arizona might have been an accidental introduction by humans. The species has been recorded in Arizona since at least 1876 (Forbes \& Schaefer, 2003) and is now also known north of Mexico from California to Texas (https://bugguide.net/node/view/20163).

As a brief synopsis of the known ecology and annual phenological cycle of $T$. neocalifornicus relative to their host plant, mesquite bugs are univoltine (having one generation per year and overwintering as eggs; Jones, 1993). Eggs eclose in February, and nymphs aggregate around the eggs to use up the rest of the egg reserves and feed. Nymphs aggregate using specialized pheromones (adults do not respond to the pheromones in tests), and secrete malodorous, toxic compounds in self-defense and possibly as alarm chemicals to alert conspecifics against predator attacks. The nymphal toxins are effective on insect predators in tests; tests do not seem to have been made on vertebrate predators (Prudic et al., 2008). Nymphs feed on mesquite leaves and pods (once available), and molt through their first-fifth instars from January-July; they often migrate to the base of their host trees in summer, probably in response to high afternoon temperatures (Jones, 1993). Mesquites flower from February-March, and bear fruits (bean pods) from July-October. As nymphs, mesquite bugs are unable to fly and are aposematically colored red, white, and brownish or blackish to advertise their noxious secretions. The coloration probably deters visually oriented diurnal predators such as birds and larger invertebrate predators. Although the warning coloration might be visible to bats during twilight hours, night-active bats might be repelled by the nymphs' noxious secretions. The nymphs often stay under the foliage on the spiny branches of the mesquite canopy; they also form defensive aggregations that secrete noxious fluid from their abdomens, similar to a related species, $T$. acutangulus in Central America (Aldrich \& Blum, 1978). The adults first start to appear from the fifth nymphal instars around July-August, with the highest proportion of adults between MaySeptember. By contrast with the nymphs, the adult mesquite bugs are large and dark colored (blackish brown and dark reddish) and no longer secrete the chemicals that are toxic to small insect predators. Instead, the adults secrete a different set of noxious chemicals from those of the nymphs to trigger aggregations and in response to a simulated predator disturbance. These 
133 chemicals include hexyl acetate, hexenal, and hexanol (Prudic et al., 2008; Noge, 2015). Adult

134 pheromones are not toxic or deterrent to insect predators but might deter vertebrates such as

135 birds, a major group of predators on adult heteropteran insects (Prudic et al., 2008). Adult

136 mesquite bugs feed in the mesquite trees until late summer, then breed and lay eggs on mesquite

137 stems and under bark in late summer-early fall. Females start ovipositing around August and

138 continue through October, when the mesquite trees start dropping their leaves (October-January).

139 They overwinter only in the egg stage (Jones, 1993).

140

141

142

143

144

145

146

147

148

149

150

151

152

153

154

155

156

157

158

159

160

161

162

163

164

165

166

During 1994-1996, in the process of studying bats roosting in soil-piping cavities in southern Arizona (Van de Water \& Peachey, 1997), we observed reddish guano and culled wings of mesquite bugs beneath a pallid bat night roost. Collecting these discarded fragments eventually grew into the present contribution to knowledge of the behavior of mesquite bugs and the diet of pallid bats.

\section{MATERIALS AND METHODS}

In the process of observing and studying Mexican long-nosed bats at the Cienega Creek Natural Preserve under Arizona Game and Fish Commission permit I-96-024, one of us (WDP) discovered guano and insect parts beneath a night roost of pallid bats in one of several soilpiping cavities. Realizing the potential of these discarded remains to bolster knowledge of the diet of pallid bats in this area, we searched for other such night feeding roosts in the local area and opportunistically revisited them to collect the prey remains while the bats were absent.

\section{Study area}

A small remnant mesquite bosque (bottomland forest) occurs at 1030-1060 m elevation in an abandoned meander of Cienega Creek, in the Cienega Creek Natural Preserve (CCNP), southeast of Tucson in Pima County, Arizona. Dominant plants in the bosque are velvet mesquite (Prosopis velutina) and graythorn (Zizyphus). Adjacent to the bosque, Cienega Creek flows above ground for parts of its reach where there are surface outcroppings of porphyritic andesite at the upstream and downstream limits of the reach. There the creek forms a riverine marsh or ciénaga, one of few remaining perennial reaches of the stream, and a disappearing habitat feature in the desert southwest (Turner, 1974; Hendrickson \& Minckley, 1984). The riparian area is dominated by tree species such as cottonwood (Populus), willow (Salix), ash (Fraxinus), mesquite, and the shrubs seepwillow (Baccharis) and sumac (Rhus). Cattails (Typha) grew in the water of the ciénaga. The bosque grows on a low Quaternary terrace 2-10 m above the stream channel and abruptly separated from it by vertical banks. On adjacent gravelly hills is semidesert grassland and desert scrub with palo verde (Cercidium) and saguaro (Carnegiea), accented by species of yucca (Yucca), agave (Agave), acacia (Acacia), and ocotillo (Fouquieria), with occasional juniper (Juniperus). Foothills of the Rincon Mountains occur to the north and bear junipers and oak woodland at higher elevations.

The relative representation of trees and many other plants in this area was strongly changed in historic times after colonization; the extensive removal in the 1800s of oaks and junipers for railroads and livestock overgrazing resulted in an increase in the density of mesquites (Bahre \& Hutchinson, 1985; Turner et al., 2003). As a result, Cienega Creek became entrenched and presently flows at a lower level than it did during and prior to the $1800 \mathrm{~s}$. The lowering of the water table, headward erosion, and subsurface withdrawal are removing the soil 
179 beneath the mesquite trees, exposing their roots, gullying the terraces and bosque, and forming a

180 pseudokarst terrain with natural bridges, blind and interrupted reaches, sinkholes, and

181 underground cavities through soil-piping action (Fig. 1). In CCNP, the cavities provided roosting

182 sites for night-roosting pallid bats in the summer time, as well as refuges or nesting areas at

183 various times of year for other species including other bats (Choeronycteris mexicana,

184 Corynorhinus townsendii, and Myotis velifer), woodrats (Neotoma albigula), javelinas (Pecari

185 tajacu), skunks (Conepatus leuconotus and Mephitis macroura), and a small unidentified bird

186 (personal observations). In the immediate vicinity of the soil-piping cavities, plants included

187 mesquite, graythorn, desert broom (Baccharis), cholla cactus (Cylindropuntia), grasses, and

188 small herbaceous plants. The vegetation is essentially the same on top of the flat terrace as in the

189 bottoms of the eroding gullies, except that mesquites are absent in the gully systems. As the soil

190 continues to erode, the soil-piping cavities seem to be ephemeral and might eventually disappear

191 as roosting areas for bats. Episodic roof collapse from the ceilings of the soil-piping cavities

192 occasionally covered the insect parts dropped by the bats.

193 In September 2002, we observed mesquite bugs on and under mesquite trees along a

194 normally dry tributary of Cienega Creek that had flooded the previous night during a rainstorm.

195 We also made casual observations of pallid bats in 2001 and 2002 at a day roost that was

196 discovered in the porch of a caretaker's residence at the nearby Colossal Cave Mountain Park.

197 This building roost was about $5 \mathrm{~km}$ distant from the soil-piping cavities at CCNP and at an

198 elevation of $1095 \mathrm{~m}$, about $60 \mathrm{~m}$ higher than the soil-piping cavities. Although this porch served

199 mainly as a day roost, it was also sometimes used as a night roost by pallid bats.

200

201

202

203

204

205

206

207

208

209

210

211

212

213

214

215

216

217

218

219

220

221

222

223

224

\section{Collecting methods}

Insect parts were first noted by one of us (WDP) in 1994 in one of the soil-piping cavities at Cienega Creek. In 1996, WDP discovered two additional cavities with accumulations of insect fragments and made sightings of $A$. pallidus. We chose to study the culled insect parts discarded by the pallid bats as a non-intrusive method of determining the macro-arthropodophagous diet in this bat population. Pallid bats are sensitive to disturbance at their roosts (Arroyo-Cabrales \& de Grammont 2017; O'Shea \& Vaughan 1977), thus we collected insect remains at a night roost not used by the bats during the daytime as a way to avoid interference in their activity. The pallid bats were usually absent from the soil-piping cavities when we collected samples in the daytime except on one occasion in September 2002 when we observed two individuals. We visited the cavities and collected insect parts once in November 1996, once in January 2001, twice, in February and September 2002, and once in September 2004. These did not represent seasonal samples but were merely times at which we were able to visit the soil-piping cavities and collect the remains that had accumulated since our previous visit. We collected all pieces from the larger concentrations of pallid bat prey that could easily be picked up by hand for later identification and to sample the overall diversity of species eaten, but also to estimate the relative abundance in the diet of the different insect species. Although this method possibly misses some smaller insects taken in aerial hawking flight (not a preferred mode of foraging for pallid bats; O'Shea \& Vaughan, 1977; Johnston \& Fenton, 2001), our study reinforces previously published data about the contribution of prey brought into night roosts to the total diet of pallid bats. We identified insect parts by comparison with intact museum specimens in the Oklahoma Museum of Natural History, Section of Recent Invertebrates, with descriptions in the literature, and with digital images and relevant data archived online (e.g., www.Bugguide.net). Individual prey parts and specimens collected in this study will be accessioned into the Department of Recent 
225

226

227

228

229

230

231

232

233

234

235

236

237

238

239

240

241

242

243

244

245

246

247

248

249

250

251

252

253

254

255

256

257

258

259

260

261

262

263

264

265

266

267

268

269

270
Invertebrates at the Sam Noble Oklahoma Museum of Natural History, where the data will be cataloged and made freely available to the public through GBIF and iDigBio online portals.

On 11 September 2002 we made observations and photographed mesquite bug behavior in the mesquite bosque in late afternoon and early evening. We observed apparent end-of-season mating and mortality of adult insects. We also recorded air temperatures and relative humidity with a handheld electronic sensor outside one of the pallid bat night-roosting cavities during the sundown-to-dark transition period to investigate the relationship of temperature and humidity on adult activities late in the season. On the same date, we collected several of the dead and dying mesquite bugs as voucher specimens. We inferred the sex of the mesquite bugs eaten using sexually dimorphic hind leg parts (Schuh \& Slater, 1995).

\section{RESULTS}

Among the insects observed at CCNP, mesquite bugs were common in the bosque, active and feeding on mesquites. They followed the typical phenological cycle for tropical areas described in the Introduction. We observed mesquite bugs as nymphs only early in the warm season (Fig. 2). By late summer and early fall, all Thasus observed in the ciénaga area were adults. In late summer the mesquite bugs could be seen flying all over the bosque, alighting on the trees, and mating. When summer heat slowed, evapotranspiration was high, and there was a marked diurnal-nocturnal temperature shift. Cooler air drains from the nearby mountains and a strong down-canyon breeze flows into the bosque and ciénaga. By the end of September and early October, the bugs continued mating but appeared to be succumbing to end of season mortality, possibly due to intolerance of the decreasing nighttime temperatures. At this time of year they became inactive at night and remained exposed on the periphery of the canopy. On 11 September 2002, after the first few nights during which the temperatures started to drop below about $21^{\circ} \mathrm{C}$ and the bugs were clustered out on the edges of the branches, we observed individuals become immobile while mating, laying eggs, dying, and falling to the ground (Fig. 2). During the sundown-to-dark transition period on this same date, air temperature decreased by $4.2^{\circ} \mathrm{C}$, from $25.2^{\circ}$ to $21.0^{\circ}$, while relative humidity increased by $16 \%$, from $69 \%$ to $85 \%$. Upon examination, the fallen bugs on the ground beneath mesquites occurred singly or sometimes in mated pairs (one male and one female in each case). We collected three pairs of the dead ones off the ground as voucher specimens.

By 29 September 2002, no live adult mesquite bugs were present in the vicinity of the roosting cavities of CCNP. This was probably due to cold air drainage through the bottomland, because live adults were active in nearby upland areas on the same date. On this date, pallid bats also night-roosted on the caretaker's building porch in the upland, and many moth wings but no mesquite bug parts were observed beneath the bats. On the night of 1 October 2002, the bats were again present in the porch roost but no new culled insect parts appeared, and the number of pallid bats dwindled until 7 October when only 1 or 2 were present, and no guano was present.

Pallid bats used only three of six available soil-piping cavities in the CCNP mesquite bosque as night roosts during our study, although the other three cavities were sometimes utilized by other species of bats, especially Choeronycteris mexicana (Mexican long-tongued bat) in the summer. The soil-piping cavities (Fig. 1) offered several characteristics that make them suitable as night roosts for pallid bats: (1) enclosed space providing protection from the weather and nocturnal flying predators; (2) easy access with from one to three entrances of 
271 relatively large dimensions; (3) relatively spacious interior (in this aspect the cavities were 272 somewhat like the daytime roosts described by Vaughan \& O'Shea, 1976) mostly unobstructed 273 except for occasional exposed mesquite roots; (4) high ceilings and steep walls, providing safety 274 from ground and climbing predators, respectively; (5) rough ceiling surface texture providing to at least one observed day roost.

Within the soil-piping cavities, the insect pieces dropped by the bats were concentrated across a small area of the floor on clods of collapsed soil that had fallen from the ceiling (Fig. 1c, d). Large guano pellets, often stained red from the mesquite bugs, attributable to the pallid bats occurred within the concentrations of culled insect parts on the floor of the cavities. Uncommon and scattered insect parts were occasionally found distant from these concentrations in the same soil-piping cavities, and probably represented prey remains culled by other species of bats. Three other species of bats were observed using the cavities rarely. Two of these were smaller species than Antrozous pallidus (which has a body weight of 20-35 g; Harvey et al., 2011). On one occasion, we observed four cave myotis, Myotis velifer (12-15 g) clustered in a small soil pipe in the ceiling not far from one of the cavities used by A. pallidus. On two consecutive days in January 2001 in a different area we observed an individual of Townsend's big-eared bat, Corynorhinus townsendii $(8-14 \mathrm{~g})$, in hibernation. Because the isolated insect fragments could have represented feeding by these other species, they were not collected or included in our study. The guano pellets of these smaller bat species were smaller than pallid bat guano and were never stained red like the pallid bat scats. For pallid bats, mean scat diameter $=3.1 \mathrm{~mm}$, mean length $=$ $7.8 \mathrm{~mm}(n=23)$; for Townsend's big-eared bats, mean diameter $=1.9 \mathrm{~mm}$, mean length $=3.8$ $\mathrm{mm}(n=7)$; for cave myotis, mean diameter $=2.0 \mathrm{~mm}$, mean length $=4.0 \mathrm{~mm}(n=14)$. The Mexican long-tongued bat, C. mexicana (10-25 g), also used soil-piping cavities at CCNP, but it was never found roosting in the same cavity as pallid bats. The Mexican long-tongued bat is a specialized nectar and pollen feeding bat whose guano lacks visible insect fragments, is primarily composed of pollen sometimes with bits of anthers and filaments from the stamens, and forms yellowish or reddish-brown splats beneath its roosts rather than pellets, similar to that of other nectar-and-pollen feeding bats (pers. observ.). Large, red-stained guano pellets exactly like the pallid bat scats in the soil-piping cavities accumulated on plastic sheets laid beneath the roost on the porch of the caretaker's building, indicating that at times, both groups of pallid bats were feeding on mesquite bugs.

Only one non-insect prey item was found beneath the pallid bat night roosts, a partial bat wing with metacarpals II-III-IV, phalanges, and a bit of attached membrane of the wing tip. The proximal ends of the metacarpals are morphologically distinct from those of the vespertilionid bats of the Cienega Creek area, and represent those of the phyllostomid, Choeronycteris mexicana. The distal ends of the metacarpals and the phalanges have the epiphyses completely fused, indicating an adult bat. The skin attached to the wing bones showed some signs of feeding by decomposer arthropods, indicating that the wing had been beneath the pallid bat roost for some time before it was collected in February 2004.

Pallid bats foraging in and around the mesquite bosque clearly used the soil-piping cavities as a place to hang and process insects they catch. Pallid bats are equipped with robust jaws and teeth for their body size, including longitudinally curved, tapered canines with four heavy crests or flanges on the anterior, lingual, posterior, and labial surfaces running from the apex to the base of the tooth crown, with deep furrows between all except the anterior and labial flanges (Fig. 3a-b). These canines are adapted for procuring and puncturing the exoskeletons of 
317 hard-bodied insects. The flanges of the canines create stress and propagate cracks in the chitin, 318 making it easier to penetrate the exoskeleton (see Freeman, 1979; 1992; 1998; Freeman \&

319 Weins, 1997) and subdue an insect. The tooth marks of the bats are readily seen on many of the

320

321

322

323

324

325

326

327

328

329

330

331

332

333

334

335

336

337

338

339

340

341

342

343

344

345

346

347

348

349

350

351

352

353

354

355

356

357

358

359

360

361

362 culled fragments (Fig. 3c-i).

At Cienega Creek, pallid bats fed on at least 36 species of large insects (approximately 25-60 mm body length) based on parts discarded beneath the night roosts (Table 1). Of these insects, 20 taxa are reported for the first time in the diet of $A$. pallidus. No arthropod groups other than insects were represented. All exoskeletal parts appeared to be those of adult insects. We found no evidence that the pallid bats fed upon the noxious nymphs of mesquite bugs. The insects eaten include mainly night-active forms, many of which are ground dwelling, although a few diurnal taxa including several grasshoppers, two long-horned beetles, and a dragonfly were taken.

In terms of relative abundance, the vast majority of insects consumed by pallid bats at all three cavity roosts were adult mesquite bugs. This insect also accounted for many of the bat guano pellets being reddish. Of 483 total identified insect parts, 429 (88.8\% frequency) were of mesquite bugs. All body parts of the mesquite bugs are represented, but mostly the least nutritious and most chitinous portions (wings, legs, antennae) were discarded; relatively few abdomens were found beneath the bat roosts (Table 2). Thus, pallid bats were eating mainly the abdomens of the mesquite bugs. Interestingly, the relatively few available remains of Thasus abdomens showed that the softer, ventral portion was selectively eaten and the remainder of the abdomen discarded. Of the identified Thasus parts, 272 forewings (Table 2) indicate a minimum of 136 individual mesquite bugs eaten. In most samples there were more male than female mesquite bug hindleg elements, although in one sample there were more female than male hindleg elements. For insect species other than mesquite bugs, relative abundance was low, representing only one to four individuals of most species. One exception to this was the gray bird grasshopper, Schistocerca nitens, represented in February 2002 by 19 forewings and 57 hindwings.

\section{DISCUSSION}

Ross (1967) and subsequent authors have compiled a long list of arthropod prey species taken by pallid bats. Our results add 18 taxa not previously recorded as pallid bat prey to the overall list. Pallid bats in our study fed upon large moths as well as large beetles; Freeman \& Lemen (2007) indicated that beetles were about 3.2 times harder than moths of the same body size, but that body size or volume of the insect also was important in cuticle toughness. Freeman \& Lemen (2007) hypothesized that, as aerial feeders, some bats must limit the upper size of insects they eat, because insects that are too large cannot be processed orally in flight, especially for a bat species that depends on being able to continue echolocating to fly. Some bats might capture prey that are too tough to process in flight and must land to process them. These authors also hypothesized that harder insects might take longer for bats to chew and thus limit the upper size of certain taxa of insects taken, which varies among insect taxa.

In our study, the higher numbers of large, armored, and cumbersome legs and other body parts of mesquite bugs found beneath roosts relative to other taxa of insects suggests that mesquite bugs are more difficult for pallid bats to process than other kinds of insects. Mesquite bugs have a small head, thorax, and abdomen with large legs relative to most of the beetles and 
363 moths in the bats' diet. Perhaps the relative ease with which mesquite bugs are located or secured

364 in late summer or early autumn counterbalances the energy and time needed to commute to a

365 night roost to process them. The size and hardness of the insects eaten by pallid bats suggests

366 there is a large upper size limit to what insects pallid bats are capable of processing and eating.

367 Mesquite bugs (Thasus) are among the largest terrestrial heteropterans known (Forbes \&

368 Schaefer, 2003) and are $28-43 \mathrm{~mm}$ in body length. The relative abundance of their body parts

369 recovered in the soil-piping cavities leads us to hypothesize that the availability of the cavities

370 and their proximity to the mesquite bosque enhanced their usage by pallid bats as a place to

371 process a seasonally abundant source of food.

372

373

As noted above, most of the insects eaten by the pallid bats are nocturnal, although several species represented in our study are diurnal. Most day-active insects are inactive at night.

374 Therefore, for bats that must be able to hear prey-generated sounds of motion to find prey, our

375

376

377

378

379

380

381

382

383

384

385

386

387

388

389

390

391

392

393

394

395

396

397

398

399

400

401

402

403

404

405

406

407

408 prey list largely supports the assertion of Fuzessery et al. (1993) that pallid bats are hunting primarily with sound cues and are less dependent on visual cues. Many of the large insects consumed by pallid bats in this study make noise in flight, while others have been variously described as noisy fliers (e.g., Cotinis mutabilis; Tallamy, 2009).

Furthermore, in spiny mesquite foliage, the bats probably avoid flying in the understory or within the tree canopy to hunt for prey they cannot hear. The risk of injury is too high unless they can be certain there is potential food available there, like katydids, mesquite moths, and mesquite bugs.

As adults, mesquite bugs do not secrete the same compounds as a defense against insect predators that they do as nymphs. Most insect predators are not interested in the non-toxic adults because the bugs are so big. For the mesquite bugs, it might not be evolutionarily worthwhile to invest energy in producing toxic compounds against other insect predators when it is unnecessary. The adult bugs switch to a defense of muted colors (thus being more cryptic to visually-oriented aerial predators), and a physically more armored exoskeleton (spiny hind legs, tougher wings), but less noxious chemicals than nymphs. We hypothesize that this is not necessarily a change to prevent predation as much as a trade-off of putting less investment in defense (producing energetically expensive coloration and toxins) and more investment into reproduction (wings provide mobility to find mates, less toxic chemical investment for short period of mating and death).

As noted earlier, in laboratory experiments pallid bats showed an aversion to the odor of a Pinacate beetle Eleodes (Johnston, 2002); however, at least one species of Eleodes, E. acuticauda, has been reported as a prey item for pallid bats (Orr, 1954:232), and the genus also appeared as prey in our study. Perhaps the bats are able to process and discard the noxious parts of certain insects as well as the armored hard parts. Although the chemicals secreted by adult mesquite bugs differ from those of nymphs (chemical components frequently change after metamorphosis; Noge, 2015), the adult compounds have not been tested with vertebrates, so it is unknown whether the chemicals produced by the adult bugs actually deter vertebrate predators (Prudic et al., 2008). Of the secretions produced by the adult bugs (hexyl acetate, hexanal, 1hexanol and possibly others), hexyl acetate and hexanal might be aggregational pheromones directed toward other mesquite bugs (Prudic et al., 2008; Noge, 2015). Given that pallid bats in our study never ate nymphs, the nymphal secretions might be effective not only against insect predators but also against bats. And given the frequency with which pallid bats ate the adults, either the adult bugs are non-noxious to pallid bats or else the bats are not susceptible or averse to their secretions. 
409

410

411

412

413

414

415

416

417

418

419

420

421

422

423

424

425

426

427

428

429

430

431

432

433

434

435

436

437

438

439

440

441

442

443

444

445

446

447

448

449

450

451

452

453

454

The only non-insect prey item found at a pallid bat night roost in this study was another bat, the flower-visiting phyllostomid Choeronycteris mexicana. As noted above, C. mexicana utilized separate but adjacent soil-piping cavities at CCNP in summers during our study. There is one previous record of pallid bats eating a Mexican free-tailed bat, Tadarida brasiliensis, although the predation occurred while the two species were in captivity, being held together in the same cage from which the smaller free-tailed bats were unable to escape (Engler, 1943). Thus, the $C$. mexicana at CCNP is the first recorded instance in the wild of predation by $A$. pallidus on another species of bat.

Many kinds of animals take advantage of situations arising as they acquire food (Young, 2012). Like many predators, various species of bats are opportunistic on hatches of insects (e.g., Myotis [Vespertilionidae], Fenton \& Morris, 1976; Lavia frons [Megadermatidae], Vaughan \& Vaughan, 1986; Dial \& Vaughan, 1987; Taphozous melanopogon [Emballonuridae], Hipposideros sp. [Hipposideridae], and Scotophilus temminckii [Vespertilionidae], Gould, 1978; Hipposideros gigas [Hipposideridae], Vaughan, 1977; Nycteris grandis [Nycteridae], Fenton et al., 1993) and also passively use sounds produced by the insects rather than actively echolocating them. Several of the large insects preyed upon are noisy fliers, and pallid bats might thus detect them easily. Some, like antlions, are poor fliers as adults (Merlin, 2003). At CCNP, opportunistic feeding was associated with high selectivity for a single prey species that could make wide searches for patches of food energetically worthwhile.

The body parts discarded versus parts eaten indicates that pallid bats take the most easily digestible and probably most nutritious parts of mesquite bugs. The abdomens of gravid female bugs filled with egg masses in particular might provide additional protein. When mesquite bugs are clustered and immobile on the periphery of the mesquite canopy, bats can likely capture the bugs easily compared to within the thorny canopy. Mated females move from the periphery deeper into the mesquite tree canopy to find appropriate places to deposit their eggs, and thus are less susceptible to being located and preyed upon compared to males, which might explain the male bias in our samples. The noxious and aposematic defenses of the nymphs, which are unable to fly, render them relatively immune to attack at night by the bats perhaps due to their odor and quieter movements, and to visually-oriented predators like birds during the day (or bats during twilight). By becoming immobile overnight after they alight on mesquite foliage at evening twilight, the bugs might avoid detection by bats. The noisy flight and possibly other movements and activities of the mesquite bugs, beetles, grasshoppers, and other large insects has been little studied and could be an important aspect of the bat-insect relationship. Similarly, the influence of anthropogenic noise (e.g., automobile traffic, railroad noise, air traffic) on a passive-sound-using predator limits the pallid bats' foraging efficiency and potentially their ability to utilize certain areas for foraging (Bunkley \& Barber, 2015; Bunkley et al., 2015).

Unfortunately, in this study we were unable to collect data seasonally or regularly, but a seasonal or monthly collection of dietary data would provide a good future study to pursue this ecological relationship in greater depth. Moreover, the bats might select mesquite bugs as prey only when the bugs are the most vulnerable: in late summer or early autumn after the adult females laid the eggs for the overwintering generation, and when falling nighttime air temperatures, local cool air drainage from the adjacent mountains and foothills, and high evapotranspiration might slow the insect's activity or mobility. Finally, the overwhelming majority of insects consumed in the night roosts were mesquite bugs locally derived from the mesquite bosque; the bats consumed other kinds of insects almost incidentally. In addition to their ability to endure injuries and heal (Davis, 1968), the dietary plasticity shown by pallid bats 
455

456

457

458

459

460

461

462

463

464

465

466

467

468

469

470

471

472

473

474

475

476

477

478

479

480

481

482

483

484

485

486

487

488

489

490

491

492

493

494

495

496

497

498

499

500 across the species' broad geographic range might help to lessen their risk of extinction (Boyles \& Storm, 2007) in the face of anthropogenic environmental upset and climate change.

\section{CONCLUSIONS}

The diet of pallid bats can be investigated non-intrusively by visiting their temporary-use night roosts during the day while the bats are away at separate day roosts. However, the night roosts possibly yield evidence only of those foods that are large enough to require transport to a temporary night roost for processing of edible versus inedible parts. Adult mesquite bugs formed the predominant prey for pallid bats at the CCNP. We found no evidence of pallid bats feeding on toxic, aposematically colored nymphal stages of mesquite bugs. Adult mesquite bugs are possibly non-toxic to pallid bats, or perhaps the bats are able to tolerate the less-toxic compounds of the adult bugs. Late-season breeding and postbreeding adult mesquite bugs are exposed near the edges of the mesquite canopy and provide prey for opportunistic, foliage-gleaning pallid bats. After breeding and laying eggs that overwinter in the mesquite trees, moribund adult mesquite bugs begin to become immobile in the trees or drop from the canopy when the nighttime low temperatures at CCNP fell below $21^{\circ} \mathrm{C}$. Mesquite bugs are considered to be mostly subtropicaltropical insects that may have invaded the southwestern United States during historic times with the bringing of cattle and spread of mesquite trees; pallid bats at the CCNP are providing an important natural control on the local mesquite bug population. Their exploitation of mesquite bugs is probably enhanced by the proximity of soil-piping caves to the mesquite bosque as a place to process the insects. Pallid bats at the CCNP ate numerous taxa of large-bodied insects, consistent with their diet in many other portions of the bats' range. When mesquite bugs are observable in the local mesquite trees, their procurement by pallid bats can be determined by the presence of large reddish guano pellets $2.5-3.5 \mathrm{~mm}$ in diameter beneath local bat night roosts. Insects parts discarded beneath pallid bat roosts can be distinguished from insect parts culled by birds or other predators by distinctive tooth marks on the discarded insect parts. Bats usually ate the abdomen and thorax of mesquite bugs and most consistently discarded the wings and legs. At the CCNP, pallid bats left the remains of no arthropods other than insects. Seventeen taxa of insects were newly identified as prey for pallid bats, and reflect a diversity of local habitats of the CCNP as foraging habitat for the bats. In addition, pallid bats ate an individual of one other local species of bat, the Mexican long-nosed bat, another first recorded instance of such predation for pallid bats.

\section{ACKNOWLEDGMENTS}

We thank the insects and the pallid bats themselves for providing inspiration and endless actions to pique our curiosity. We thank Richard Packauskas for aid in the initial identification of the mesquite bug, Gene Hall, University of Arizona, for identifying a small initial collection of insect parts, Tom Bethard, Kevin Horstman, Samantha Lefevre, and Robert Pape for aid in fieldwork, Jessica Czaplewski for help in sorting insect parts, Cheryl D. Czaplewski for logistical support, and Julia Fonseca, Pima County Flood Control, for hydrological information about soilpiping. Thanks to Gale Bundrick and the Pima County Parks and Recreation Department for permission to access the area for study. We thank Melissa Sadir of the Collection of Recent 
501 Invertebrates at the Oklahoma Museum of Natural History for accessioning and cataloging insect

502 parts. We appreciate the loan of a pallid bat specimen by Brandi S. Coyner and Janet K. Braun of

503 the Collection of Mammals at the Oklahoma Museum of Natural History. We thank Steve

504 Westrop and Roger Burkhalter for the use of their bellows camera with Stackshot rig and focus-

505 stacking software to capture and process images. We appreciate the many contributors to the

506 websites: Arizona: Beetles Bugs Birds and more (Margarethe Brummermann), BugGuide.net,

507 ButterfliesandMoths.org, The Moths of Southeastern Arizona, and Wikipedia for their time and

508 efforts in providing the ease of access and helpful information that proved highly useful in

509 researching habitat and food plants for many of the insects.

510

511

512

513

514

515

516

517

518

519

520

521

522

523

524

525

526

527

528

529

530

531

532

533

534

535

536

537

538

539

540

541

542

543

544

545

546

\section{REFERENCES}

Aldrich, JR, Blum, MS. 1978. Aposematic aggregation of a bug (Hemiptera: Coreidae): the defensive display and formation of aggregations. Biotropica 10:58-61.

Aliperti JR, Kelt DA, Heady PA, Frick WF. 2017. Using behavioral and stable isotope data to quantify rare dietary plasticity in a temperate bat. Journal of Mammalogy 98:340-349.

Ammerman LK, Hice CL, Schmidly DJ, Brown C, Altenbach JS. 2012. Bats of Texas. College Station, Texas A\&M University Press.

Arroyo-Cabrales J, de Grammont JC. 2017. Antrozous pallidus. The IUCN Red List of Threatened Species 2017-3. http://www.iucnredlist.org/details/1790/0 and http://dx.doi.org/10.2305/IUCN.UK.2017-2.RLTS.T1790A22129152.en

Bahre CJ, Hutchinson CF. 1985. The impact of historic fuelwood cutting on the semidesert woodlands of southern Arizona. Journal of Forest History 29:175-186.

Bell GP. 1982. Behavioral and ecological aspects of gleaning by a desert insectivorous bat, Antrozous pallidus (Chiroptera: Vespertilionidae). Behavioral Ecology and Sociobiology 10:217-223.

Bell GP, Fenton MB. 1986. Visual acuity, sensitivity and binocularity in a gleaning insectivorous bat, Macrotus californicus (Chiroptera: Phyllostomidae). Animal Behaviour 34:409-414.

Boyles JG, Storm JJ. 2007. The perils of picky eating: dietary breadth is related to extinction risk in insectivorous bats. PLOS ONE 2:e672.

Brailovsky H, Schaefer CW, Barrera E, Packauskas RJ. 1995 (dated 1994). A revision of the genus Thasus (Hemiptera: Coreidae: Coreinae: Nematopodini). Journal of the New York Entomological Society 102:318-343.

Brummermann M. 2010. Life cycle of the giant mesquite bug, Thasus neocalifornicus. http://arizonabeetlesbugsbirdsandmore.blogspot.com/2010/06/life-cycle-of-giantmesquite-bug-thasus.html Accessed 14 September 2016.

Bunkley JP, Barber JR. 2015. Noise reduces foraging efficiency in pallid bats (Antrozous pallidus). Ethology 121:1116-1121.

Bunkley JP, McClure CJW, Kleist NJ, Francis CD, and Barber JR. 2015. Anthropogenic noise alters bat activity levels and echolocation calls. Global Ecology and Conservation 3:6271.

Davis R. 1968. Wing defects in a population of pallid bats. American Midland Naturalist 79:388395.

De La Torre-Bueno JR. 1945. Random notes on Thasus acutangulus. Bulletin of the Brooklyn Entomological Society 40:83. 
547 Dial KP, Vaughan TA. 1987. Opportunistic predation on alate termites in Kenya. Biotropica 19:185-187.

Engler CH. 1943. Carnivorous activities of big brown and pallid bat. Journal of Mammalogy 24:96-97.

Fenton MB, Morris GK. 1976. Opportunistic feeding by desert bats (Myotis spp.). Canadian Journal of Zoology 54:526-530.

Fenton MB, Rautenbach IL, Chipese D, Cumming MB, Musgrave MK, Taylor JS, Volpers T. 1993. Variation in foraging behavior, habitat use and diet of large slit-faced bats (Nycteris grandis). Zeitschrift für Säugetierkunde 58:65-74.

Forbes G, Schaefer CW. 2003. Further notes on the genus Thasus (Hemiptera: Heteroptera: Coreidae). Journal of the New York Entomological Society 111:235-241.

Freeman PW. 1979. Specialized insectivory: beetle-eating and moth-eating molossid bats. Journal of Mammalogy 60:467-479.

Freeman PW. 1992. Canine teeth of bats (Microchiroptera): size, shape and role in crack propagation. Biological Journal of the Linnean Society 45:97-115.

Freeman PW. 1998. Form, function, and evolution in skulls and teeth of bats. In: Kunz TH, Racey PA, eds. Bat biology and conservation. Washington, D.C.: Smithsonian Institution Press 140-156.

Freeman PW, Lemen CA. 2007. Using scissors to quantify hardness of insects: do bats select for size or hardness? Journal of Zoology 271:469-476.

Freeman PW, Weins WN. 1997. Puncturing ability of bat canine teeth: the tip. In: Yates TL, Gannon WL, Wilson DE, eds. Life among the muses: papers in honor of James S. Findley. Albuquerque: University of New Mexico Press 225-232.

Frick WF, Heady PA, Hayes JP. 2009. Facultative nectar-feeding behavior in a gleaning insectivorous bat (Antrozous pallidus). Journal of Mammalogy 90:1157-1164.

Frick WF, Price RD, Heady PA, Kay KM. 2013. Insectivorous bat pollinates columnar cactus more effectively per visit than specialized nectar bat. American Naturalist 181:137-144.

Frick WF, Shipley JR, Kelly JF, Heady PA, Kay KM. 2014. Seasonal reliance on nectar by an insectivorous bat revealed by stable isotopes. Oecologia 174:55-65.

Froeschner RC. 1988. Family Coreidae; Leach, 1915. In: Henry TJ, Froeschner RC, eds. Catalog of the Heteroptera, or true bugs, of Canada and the continental United States. New York: E.J. Brill 69-92.

Fuzessery ZM, Buttenhoff P, Andrews B, Kennedy JM. 1993. Passive sound localization of prey by the pallid bat (Antrozous p. pallidus). Journal of Comparative Physiology A 171:767777.

Gould E. 1978. Opportunistic feeding by tropical bats. Biotropica 10:75-76.

Harvey MJ, Altenbach JS, Best TL. 2011. Bats of the United States and Canada. Baltimore: Johns Hopkins University Press.

Hendrickson DA, Minckley WL. 1984. Ciénegas--vanishing climax communities of the American Southwest. Desert Plants 6:130-175.

Hermanson JW, O'Shea TJ. 1983. Antrozous pallidus. Mammalian Species 213:1-8.

Herrera M, Fleming LG, Findley JS. 1993. Geographic variation in carbon composition of the pallid bat, Antrozous pallidus, and its dietary implications. Journal of Mammalogy 74:601-606.

Hopp BH, Arvidson RS, Adams ME, Razak KA. 2017. Arizona bark scorpion venom resistance in the pallid bat, Antrozous pallidus. PLoS ONE 12:e0183215. 
593

594

595

596

597

598

599

600

601

602

603

604

605

606

607

608

609

610

611

612

613

614

615

616

617

618

619

620

621

622

623

624

625

626

627

628

629

630

631

632

633

634

635

636

637

638

Howell DJ. 1980. Adaptive variation in diets of desert bats has implications for evolution of feeding strategies. Journal of Mammalogy 61:730-733.

Johnston DS. 2002. Prey discrimination by olfactory cues in the pallid bat (Antrozous pallidus). Bat Research News 42:162.

Johnston DS, Fenton MB. 2001. Individual and population-level variability in diets of pallid bats (Antrozous pallidus). Journal of Mammalogy 82:362-373.

Jones WA. 1993. New host and habitat associations for some Arizona Pentatomoidea and Coreidae. Southwestern Entomologist, Supplement no. 16:1-29.

Lenhart PA, Mata-Silva V, Johnson JD. 2010. Foods of the pallid bat, Antrozous pallidus (Chiroptera: Vespertilionidae), in the Chihuahuan Desert of western Texas. Southwestern Naturalist 55:110-117.

Merlin P. 2003. A field guide to desert holes. Tucson: Arizona-Sonora Desert Museum Press.

Noge K. 2015. Studies on chemical ecology of the heteropteran scent gland components. Journal of Pesticide Science DOI: 10.1584/jpestics.J15-03

Orr RT. 1954. Natural history of the pallid bat, Antrozous pallidus (LeConte). Proceedings of the California Academy of Sciences 28:165-246.

O'Shea TJ, Vaughan TA. 1977. Nocturnal and seasonal activities of the pallid bat, Antrozous pallidus. Journal of Mammalogy 58:269-284.

Prudic KL, Noge K, Becerra JX. 2008. Adults and nymphs do not smell the same: the different defensive compounds of the giant mesquite bug (Thasus neocalifornicus: Coreidae). Journal of Chemical Ecology 34:734-741.

Rambaldini DA, Brigham RM. 2011. Pallid bat (Antrozous pallidus) foraging over native and vineyard habitats in British Colombia, Canada. Canadian Journal of Zoology 89:816822.

Ross A. 1961. Notes on food habits of bats. Journal of Mammalogy 42:66-71.

Ross A. 1967. Ecological aspects of the food habits of insectivorous bats. Proceedings Western Foundation of Vertebrate Zoology 1:205-263.

Schaefer CW, Packauskas RJ. 1997. Notes on the genus Thasus (Hemiptera: Coreidae). Journal of the New York Entomological Society 105:206-214.

Schuh RT, Slater JA. 1995. True bugs of the world (Hemiptera: Heteroptera): classification and natural history. Ithaca, New York: Cornell University Press.

Simmons NB, Wetterer AL. 2002. Phylogeny and convergence in cactophilic bats. Pages 87-121 In: Fleming TH, Valiente-Banuet A, eds. Columnar cacti and their mutualists: evolution, ecology, and conservation. Tucson: University of Arizona Press 87-121.

Tallamy DW. 2009. Bringing nature home: how you can sustain wildlife with native plants. Portland, Oregon: Timber Press.

Turner RM. 1974. Map showing vegetation in the Tucson area, Arizona. United States Geological Survey, Miscellaneous Investigations Series MAP I-844-H; scale 1:250000.

Turner RM, Webb RH, Bowers JE, Hastings JR. 2003. The changing mile revisited: an ecological study of changes with time in the lower mile of an arid and semiarid region. Tucson: University of Arizona Press.

Van de Water PK, Peachey WD. 1997. Dietary analysis of the Mexican long tongued bat Choeronycteris mexicana using pollen analysis of guano collected in Cienega Creek Natural Preserve. Abstracts of Presentations at the 27th Annual North American Symposium on Bat Research, October 8-11, Tucson, Arizona. Bat Research News $38: 133$. 
639 Vaughan TA. 1977. Foraging behaviour of the giant leaf-nosed bat (Hipposideros commersoni). $640 \quad$ East African Wildlife Journal 15:237-249.

641 Vaughan TA, O'Shea TJ. 1976. Roosting ecology of the pallid bat, Antrozous pallidus. Journal 642 of Mammalogy 57:19-42.

643 Vaughan TA, Vaughan RP. 1986. Seasonality and the behavior of the African yellow-winged 644 bat. Journal of Mammalogy 67:91-102.

645 Ward CR, O'Brien CW, O'Brien LB, Foster DE, Huddleston EW. 1977. Annotated checklist of $646 \quad$ New World insects associated with Prosopis (mesquite). Washington, D.C.: United States 647 Department of Agriculture, Agricultural Research Service, Technical Bulletin no. 1557. 648 Young J. 2012. What the robin knows: how birds reveal the secrets of the natural world. Boston: 649 Houghton Mifflin Harcourt. 
650

651

652

653

654

655

656

657

658

659

660

661

662

663

664

665

666

667

668

669

670

671

672

673

674

675

676

677

678

679

680

681

682

683

684

685

\section{FIGURE LEGENDS}

Figure $1 \mathrm{a}$ and $\mathrm{b}$, Two soil-piping cavities developed in the terrace supporting a mesquite bosque on top with mesquite roots being exposed, and grasses in the bottoms, at Cienega Creek Natural Preserve, Arizona. The cavities serve as shelters for a variety of mammals including several species of bats. Cavity in a is dark spot in center of image; cavity in b formed a temporary natural arch. c, Interior of one of the soil-piping cavities showing a scattering of culled insect parts dropped beneath a night roost of Antrozous pallidus. d, Close-up view of the scattering; note large numbers of reddish guano pellets (especially within the spotlight from photographer's headlight at lower left), colored by the contents of mesquite bugs, numerous mesquite bug exoskeletal parts, moth wings, and beetle elytra. Photos 1a and 1b by W. D. Peachey; photos 1c-1e by N. J. Czaplewski.

Figure 2 Mesquite bugs, Thasus neocalifornicus, at the Cienega Creek Natural Preserve, Arizona. a, T. neocalifornicus nymph ( $5^{\text {th }}$ instar), with aposematic coloration indicating its noxious nature. $b$, adult, not to same scale as nymph. $c$, adults mating on a mesquite branch at dusk (with flash). d, breeding adults clustered on the peripheral foliage of mesquite at dusk in September 2002 (with flash). e, scattered dead adults on the ground representing a $<24$-hour accumulation after a rainstorm had swept away other debris. Photos by N. J. Czaplewski.

Figure 3 a and b, Stereopair photograph of the upper teeth and anterior palate of a skull of Antrozous pallidus (anterior is toward the top of the image) showing the robust upper canines with strong longitudinal flanges, which help to penetrate and puncture thick chitin. Incisors and premolars are also visible. c-i, Pieces of the exoskeletons of insects discarded by A. pallidus, showing tooth punctures caused by the bats. c, elytron of a beetle Chrysina gloriosa (Scarabaeidae); d, Same as c, close-up of area enclosed by red rectangle in c, rotated $90^{\circ}$ counterclockwise and enlarged to show tooth punctures. e, elytron of a dung beetle Dichotomius colonicus (Scarabaeidae). f, hind leg of mesquite bug Thasus neocalifornicus (Coreidae). g, elytron of Cyclocephala (Scarabaeidae). h, elytron of Xyloryctes thestalus (Scarabaeidae). i, head, thorax, and partial elytra of darkling beetle Stenomorpha marginata (Tenebrionidae). Scale bar in each image is in mm. Photos by N. J. Czaplewski. 


\section{Figure 1}

Plate of four photos, a-d, showing soil-piping cavities, culled insect parts, and bat guano.

( $a$ and b) Two soil-piping cavities developed in the terrace supporting a mesquite bosque on top with mesquite roots being exposed, and grasses in the bottoms, at Cienega Creek Natural Preserve, Arizona. The cavities serve as shelters for a variety of mammals including several species of bats. Cavity in a is dark spot in center of image; cavity in b formed a temporary natural arch. (c) Interior of one of the soil-piping cavities showing a scattering of culled insect parts dropped beneath a night roost of Antrozous pallidus. (d) Close-up view of the scattering; note large numbers of reddish guano pellets (especially within the spotlight from photographer's headlight at lower left), colored by the contents of mesquite bugs, numerous mesquite bug exoskeletal parts, moth wings, and beetle elytra. Photos $1 \mathrm{a}$ and $1 \mathrm{~b}$ by W. D. Peachey; photos 1c-1e by N. J. Czaplewski. 


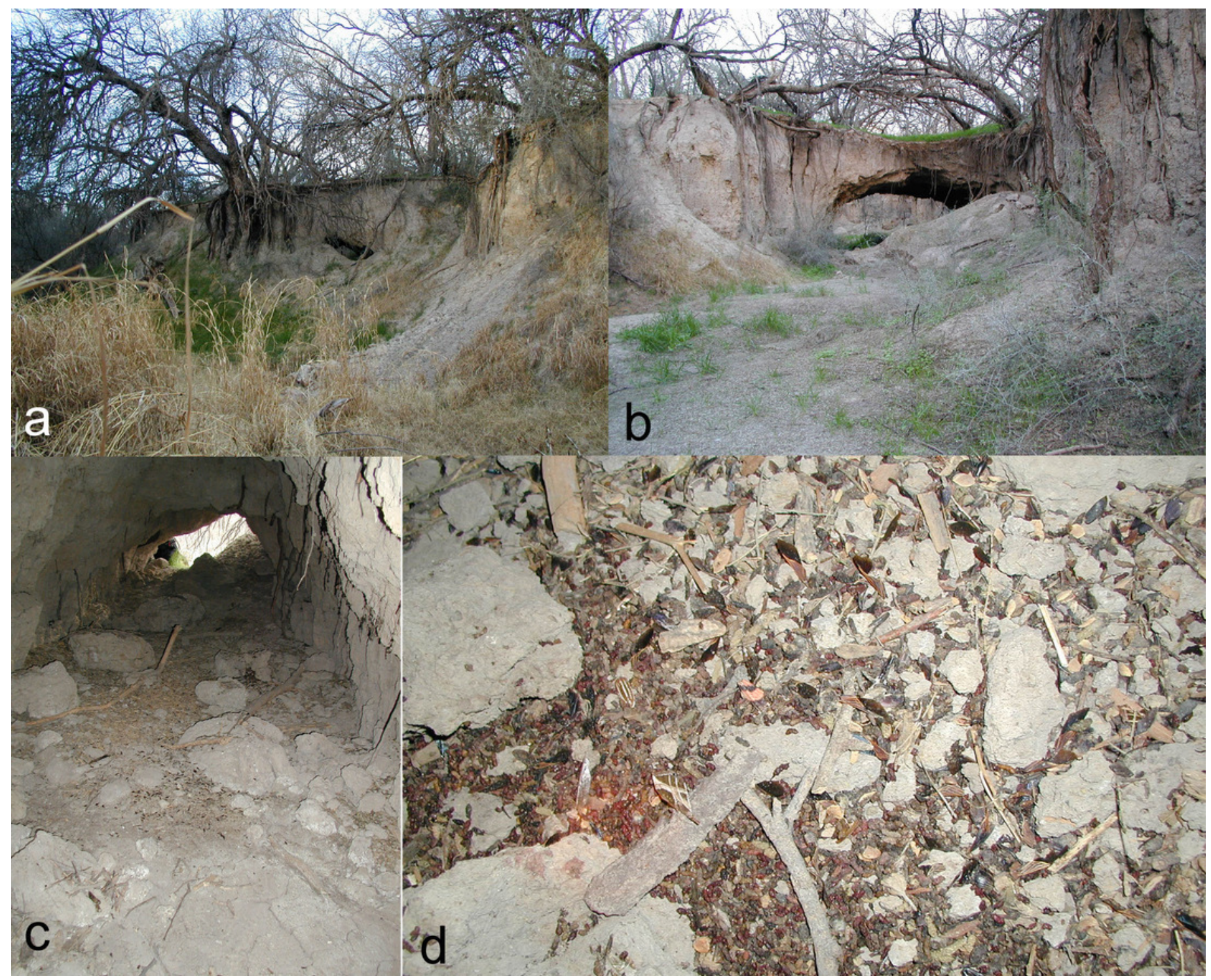




\section{Figure 2}

Plate of several photos (a-e), showing mesquite bug nymph, adult, mating adults, clustered adults on mesquite, dead adults on the ground.

Mesquite bugs, Thasus neocalifornicus, at the Cienega Creek Natural Preserve, Arizona. (a) T. neocalifornicus nymph ( $5^{\text {th }}$ instar), with aposematic coloration indicating its noxious nature. (b) adult, not to same scale as nymph. (c) adults mating on a mesquite branch at dusk (with flash). (d) breeding adults clustered on the peripheral foliage of mesquite at dusk in September 2002 (with flash). (e) scattered dead adults on the ground representing a <24hour accumulation after a rainstorm had swept away other debris. Photos by N. J. Czaplewski.

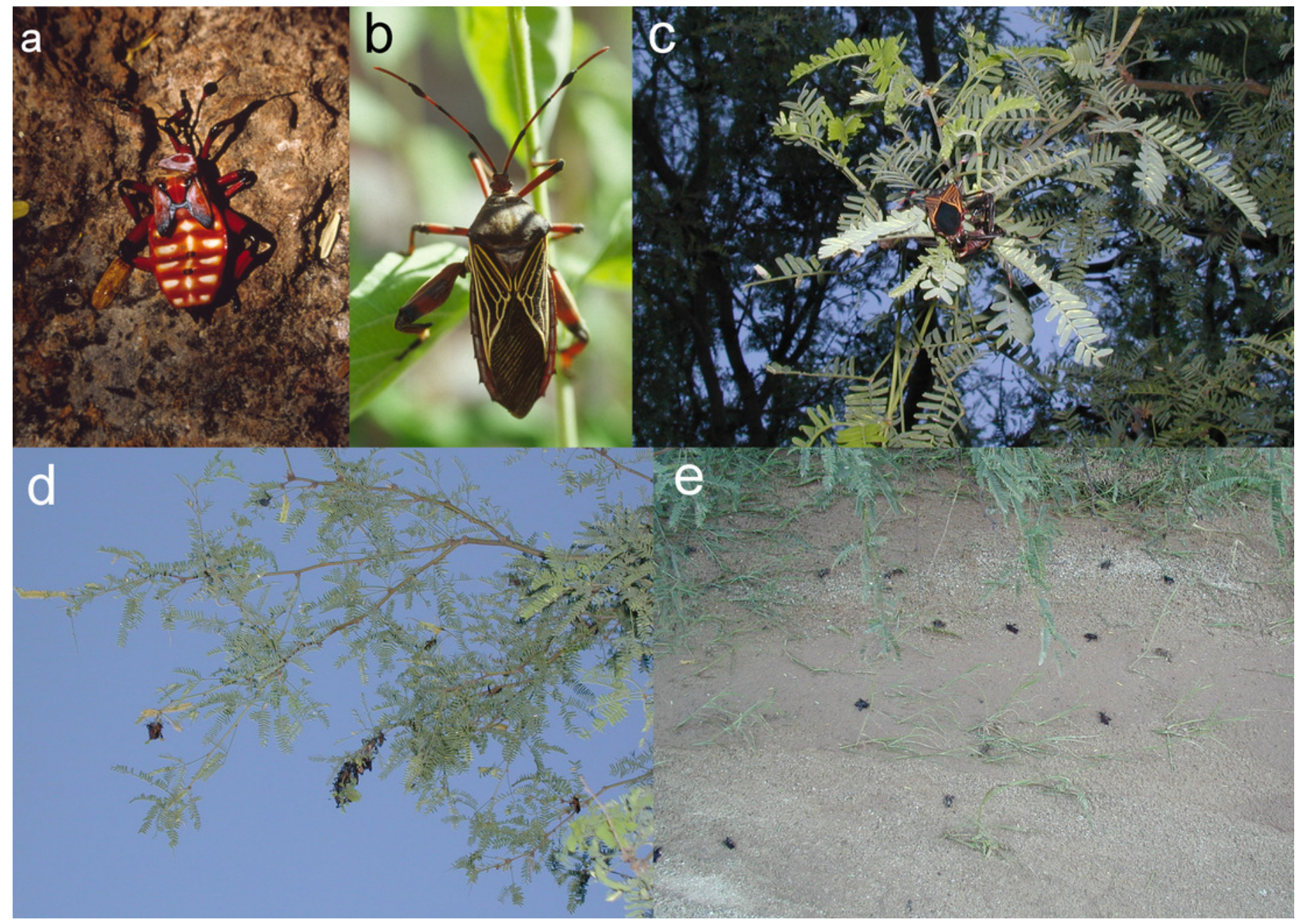




\section{Figure 3}

Stereopair of bat teeth and insect fragments.

$a$ and $b$, Stereopair photograph of the upper teeth and anterior palate of a skull of Antrozous pallidus (anterior is toward the top of the image) showing the robust upper canines with strong longitudinal flanges, which help to penetrate and puncture thick chitin. Incisors and premolars are also visible. c-i, Pieces of the exoskeletons of insects discarded by A. pallidus, showing tooth punctures caused by the bats. c, elytron of a beetle Chrysina gloriosa (Scarabaeidae); d, Same as c, close-up of area enclosed by red rectangle in c, rotated $90^{\circ}$ counterclockwise and enlarged to show tooth punctures. e, elytron of a dung beetle Dichotomius colonicus (Scarabaeidae). $\mathrm{f}$, hind leg of mesquite bug Thasus neocalifornicus (Coreidae). g, elytron of Cyclocephala (Scarabaeidae). h, elytron of Xyloryctes thestalus (Scarabaeidae). i, head, thorax, and partial elytra of darkling beetle Stenomorpha marginata (Tenebrionidae). Scale bar in each image is in $\mathrm{mm}$. Photos by N. J. Czaplewski. 


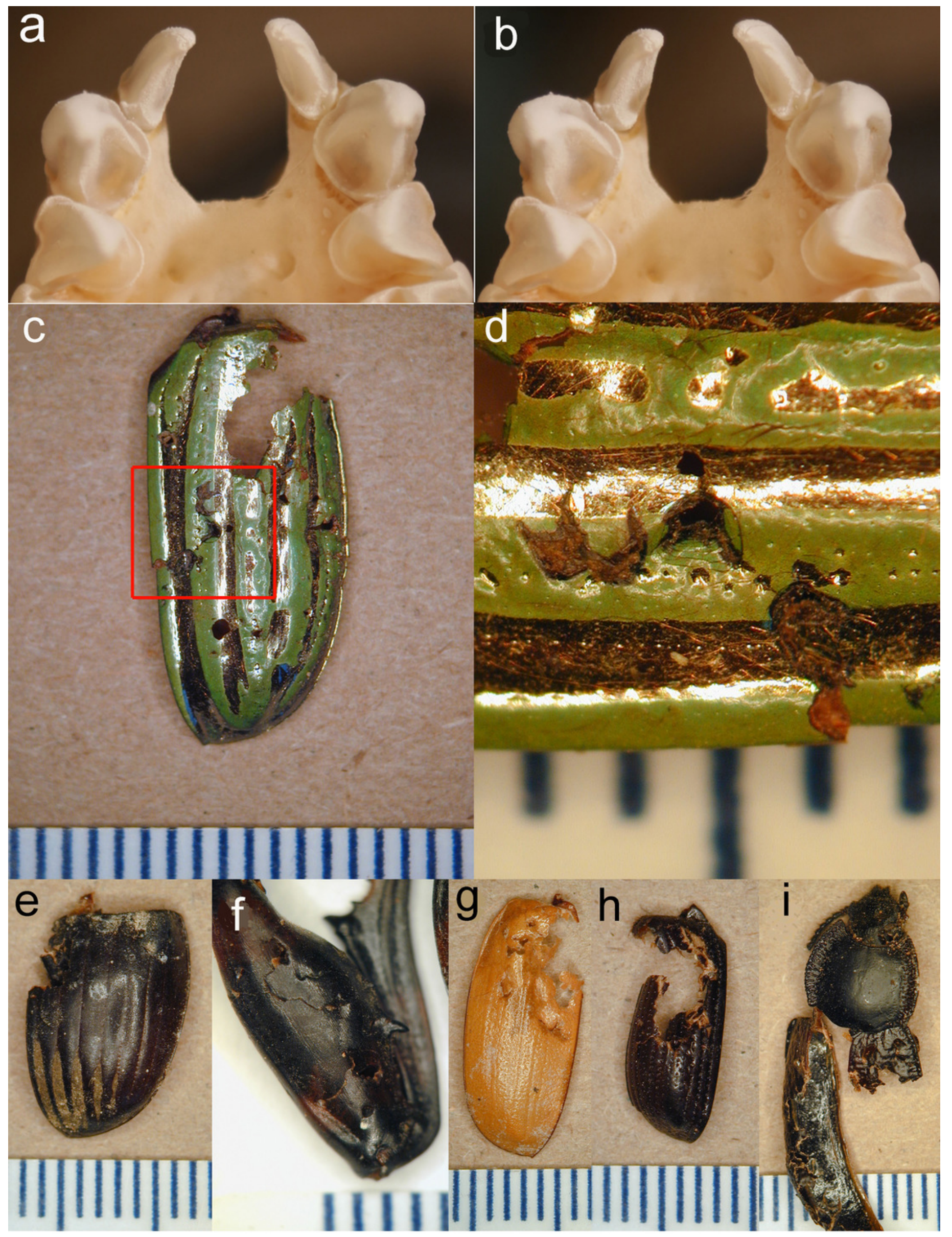




\section{Table $\mathbf{1}$ (on next page)}

List of insects and one bat identified from culled body parts deposited beneath pallid bat roosts at Cienega Creek, Arizona.

*Indicates new record of prey consumed by pallid bats. 
1 Table 1 List of insects and one bat identified from culled body parts deposited beneath 2 pallid bat roosts at Cienega Creek, Arizona. *Indicates new record of prey consumed by pallid 3 bats. Fourth column shows number of identified body parts and percentage of total when over $41 \%$.

\begin{tabular}{|c|c|c|c|}
\hline Hemiptera & Coreidae & Thasus neocalifornicus mesquite bug & $1303(88 \%)$ \\
\hline \multirow[t]{18}{*}{ Coleoptera } & Scarabaeidae & Chrysina gloriosa glorious scarab & 1 \\
\hline & & Polyphylla decemlineata ten-lined June beetle & 4 \\
\hline & & *Strategus aloeus ox beetle & 1 \\
\hline & & Strategus sp. ox beetle & 12 \\
\hline & & ${ }^{*}$ Xyloryctes thestalus rhinoceros beetle & 1 \\
\hline & & Cyclocephala sp. masked chafer & 1 \\
\hline & & *Dichotomius colonicus dung beetle & 1 \\
\hline & & Cotinis mutabilis green fig beetle & 2 \\
\hline & & Tomarus sp. carrot beetle & 1 \\
\hline & & Phyllophaga sp. May beetle & 1 \\
\hline & Tenebrionidae & *Stenomorpha marginata darkling beetle & 2 \\
\hline & & Stenomorpha sp. darkling beetle & 1 \\
\hline & & Eleodes sp. Pinacate or darkling beetle & 2 \\
\hline & Carabidae & Calosoma scrutator fiery searcher & 4 \\
\hline & & Pasimachus sp. ground beetle & 1 \\
\hline & Hydrophilidae & Hydrophilus sp. giant black water beetle & 1 \\
\hline & Cerambycidae & Oncideres rhodosticta mesquite girdler & 1 \\
\hline & & $*$ Prionini long-horned beetle & 1 \\
\hline \multirow[t]{7}{*}{ Orthoptera } & Tettigoniidae & Microcentrum rhombifolium greater angle-wing katydid & 2 \\
\hline & & *Neoconocephalus triops broad-tipped conehead & $17(1.1 \%)$ \\
\hline & & *Scudderia mexicana Mexican bush katydid & 6 \\
\hline & Acrididae & Schistocerca nitens gray bird grasshopper & $76(5 \%)$ \\
\hline & & Melanoplus differentialis differential grasshopper & 4 \\
\hline & & *Phlibostroma quadrimaculatum four-spotted grasshopper & 1 \\
\hline & & *Trimerotropis cyaneipennis blue-winged grasshopper & 1 \\
\hline \multirow[t]{8}{*}{ Lepidoptera } & Sphingidae & Hyles lineata white-lined sphinx & 6 \\
\hline & & *Eumorpha vitis vine sphinx & 11 \\
\hline & & *Sphinx sp. sphinx moth & 4 \\
\hline & & Manduca sexta tobacco hornworm moth & 1 \\
\hline & *Tortricidae & Indeterminate leafroller moth & 1 \\
\hline & Noctuidae & Catocala sp. underwing moth & 1 \\
\hline & Saturniidae & *Sphingicampa (=Syssphinx) hubbardi mesquite moth & 1 \\
\hline & & *Automeris iris iris-eyed silkmoth & 1 \\
\hline Neuroptera & Myrmeleontidae & *Vella fallax antlion & 2 \\
\hline Odonata & *Aeshnidae & Indeterminate darner & 1 \\
\hline Blattodea & Corydiidae & Arenivaga sp. cockroach & 1 \\
\hline Diptera & Tipulidae & *Nephrotoma sp. tiger crane fly & 1 \\
\hline Chiroptera & Phyllostomidae & *Choeronycteris mexicana Mexican long-nosed bat & 1 \\
\hline
\end{tabular}




\section{Table 2 (on next page)}

Body parts of adult mesquite bugs (Thasus neocalifornicus) discarded by night-roosting pallid bats and collected in soil-piping cavities in Cienega Creek Natural Preserve. 
$1 \quad$ Table 2 Body parts of adult mesquite bugs (Thasus neocalifornicus) discarded by night2 roosting pallid bats and collected in soil-piping cavities in Cienega Creek Natural Preserve on 3 three visits between January 2001 and September 2002, in decreasing order of abundance. $\mathrm{F}=$ 4 female, $\mathrm{M}=$ male.

5

\begin{tabular}{|l|l|l|l|}
\hline \multicolumn{1}{|c|}{ Body Parts } & \multicolumn{2}{c|}{ Number of elements collected } \\
\hline & January 2001 & February 2002 & September 2002 \\
\hline Forewings & 272 & 213 & 127 \\
\hline Leg parts, total & 183 & 43 & 99 \\
$\quad \begin{array}{l}\text { Forelegs and midlegs } \\
\text { Hind tibias }\end{array}$ & 91 & --- & 21 \\
$\quad$ Hind femurs & $52(12 \mathrm{~F}, 40 \mathrm{M})$ & $22(8 \mathrm{~F}, 14 \mathrm{M})$ & $57(21 \mathrm{~F}, 36 \mathrm{M})$ \\
\hline Hindwings & $40(13 \mathrm{~F}, 27 \mathrm{M})$ & $21(7 \mathrm{~F}, 14 \mathrm{M})$ & $31(20 \mathrm{~F}, 11 \mathrm{M})$ \\
\hline Isolated antennae & 40 & 45 & 56 \\
\hline Thorax (dorsal portion) & 9 & --- & 0 \\
\hline Heads with attached antennae & 8 & 0 & 18 \\
\hline Abdomens & 5 & 1 & 8 \\
\hline $\begin{array}{l}\text { Thorax with attached fore- and } \\
\text { hindwings }\end{array}$ & 1 & 8 & 5 \\
\hline
\end{tabular}

6 